\title{
ANÁLISE DAS PRODUÇÕES ACADÊMICAS APRESENTADAS NA ANPED E NO GRUPECI SOBRE O PROINFANTIL ${ }^{1}$
}

\author{
Isabel Cristina de Jesus Brandão
}

\section{RESUMO}

Neste artigo, analisamos o Programa de Formação Inicial para Professores em Exercício na Educação Infantil (Proinfantil) a partir das produções acadêmicas apresentadas no Seminário de Grupos de Pesquisa sobre Crianças e Infâncias (Grupeci) e nas Reuniões da Associação Nacional dos Pós-Graduandos em Educação (Anped) no período de 2008 a 2015. O Proinfantil foi implementado pelo governo federal no ano de 2005. A pesquisa caracterizase como estudo documental. Foi possível verificar que o Proinfantil trouxe contribuições importantes para a formação dos profissionais que não tinham o magistério, apesar do seu caráter emergencial e dos diversos problemas enfrentados para a sua concretização. Entre os avanços, consideramos a abordagem teórica de temas relacionados à Educação Infantil e os registros feitos pelas professoras por meio do memorial. Esse instrumento configura-se como importante registro de memórias de uma política pública, o qual traz colaborações significativas para as pesquisas na área. Consideramos retrocesso atribuir ao professor a responsabilidade da mudança na educação após a formação obtida no Programa, pois não foram efetivadas mudanças estruturais, por meio de políticas públicas, nos municípios em que o Programa foi posto em prática.

Palavras-chave: Proinfantil; Formação de Professor; Políticas Públicas.

\section{ANALYSIS OF ACADEMIC PAPERS PRESENTED AT ANPED AND GRUPECI ABOUT THE PROINFANTIL}

\begin{abstract}
In this article we analyze the Initial Training Program for Acting Teachers in Early Child Education (Programa de Formação Inicial para Professores em Exercício na Educação Infantil - Proinfantil) through the academic production presented at the Seminar of Research Groups about Children and Childhoods (Grupeci) and in the anual meeting of the National Association of Pos-Graduation on Education (Anped) between 2008 and 2015. The Federal Government implemented the Proinfantil in 2005. The research is a documental study. We were able to verify that inspit of the emergency characteristic of the program and problems faced in order to make it happen, the Proinfantil largely contributed to the training of teachers who didn't have the proper training. Amongst the contribution are the theoretical approaches to early childhood education related themes and the documentation produced by the teachers in the form of memorials. This documentation is an important record of the policy memory that bring relevant contribution to the research in the field. We consider that ascribing the responsibility of educational changes after the training on the teachers themselves is a throwback, for structural changes had not taken place in the form of new policies in the cities where the program was implemented.
\end{abstract}

Keywords: Proinfantil; Tacher Tbraining; Policies. 


\title{
Introdução
}

Este trabalho tem por objetivo analisar o Programa de Formação Inicial para Professores em Exercício na Educação Infantil a partir das produções acadêmicas apresentadas no Seminário de Grupos de Pesquisa sobre Crianças e Infâncias (Grupeci) e nas Reuniões da Associação Nacional dos Pós-Graduandos em Educação (Anped) no período de 2008 a 2015. Este é um recorte da pesquisa que desenvolvemos no pós-doutorado sobre o Proinfantil, na qual analisamos teses e dissertações sobre o tema.

Este tema ganhou destaque com a Lei de Diretrizes e Bases da Educação Nacional (LDBEN), Lei n. 9.394/1996, que estabelece a formação mínima do profissional para trabalhar em Educação Infantil - magistério de nível médio, na modalidade normal. Na minha vida profissional, tal temática perpassou as pesquisas realizadas durante o mestrado e o doutorado, evidenciando-se como uma área para investigação devido às lacunas sobre a história e definição do papel do professor de educação infantil.

Como destaca Batista e Rocha:

\begin{abstract}
Em estudos sobre a produção acadêmica nacional identifica-se uma lacuna quanto a investigações sobre a construção histórica da profissão docente na Educação Infantil. Entre os estudos da história da infância e da Educação encontram-se pesquisas que têm como objeto por vezes a infância, por vezes as instituições voltadas às crianças. Há também estudos que buscam as raízes da constituição do professor da escola de Ensino Fundamental, desde o período colonial até a República e a atualidade compreendendo a docência como uma construção social, porém evidenciase um hiato quando a discussão se encaminha para a constituição histórica da docência na Educação Infantil (2015, p. 2).
\end{abstract}

O ProInfantil é um curso em nível médio, a distância, na modalidade normal, cujo público-alvo são os professores de educação infantil em exercício em creches e pré-escolas das redes públicas - municipais e estaduais - e da rede privada sem fins lucrativos comunitárias, filantrópicas ou confessionais - conveniadas ou não (BRASIL 2005). Foi criado pelo governo federal no ano de 2005. É um curso que visa atender às exigências mínimas de formação de professor de educação infantil, conforme estabelece a legislação vigente. Segundo Goulart [et al.], "[...] a formação promovida pelo PROINFANTIL é apenas uma das ações dentro de um contexto mais amplo, que cria um campo propício para a construção da Educação Infantil no Brasil e para o desenvolvimento profissional de seus educadores" (GOULART et al., 2013, p. 37).

É um programa de parceria entre governo federal, estados e municípios. O governo federal foi responsável pelas elaborações das propostas técnica e financeira, pela estratégia de implementação do programa e articulação política e institucional. Os governos estaduais se responsabilizaram pela execução, acompanhamento e monitoramento do programa no âmbito estadual. Aos municípios coube efetuar o Programa e atuar diretamente com os professores cursistas e tutores.

A Lei n. 9.394/1996, no momento da sua aprovação, gerou várias polêmicas e muitas preocupações pela possibilidade de demissão dos profissionais que não atendiam aos seus requisitos. Além disso, o Plano Nacional de Educação (PNE 2001-2011, Lei n. 10.172, de 9/1/2001) definiu metas para a formação do professor. Nesse sentido, o Proinfantil surgiu com o objetivo de: 
- $\quad$ habilitar em Magistério para a Educação Infantil (EI) os professores em exercício de acordo com a legislação vigente;.

- $\quad$ elevar o nível de conhecimento e aprimorar a prática pedagógica dos docentes;

- valorizar o magistério, oferecendo condições de crescimento profissional e pessoal do professor;

- contribuir para a qualidade social da educação das crianças com idade entre 0 e 6 anos nas Instituições de Educação Infantil (IEI) (BRASIL, 2005, p. 12-13).

E estabeleceu como qualificação esperada para o professor após a conclusão do curso:

- dominar o instrumental necessário para o desempenho de suas funções de educar e cuidar das crianças;

- compreender a instituição de educação infantil como espaço coletivo de educar e cuidar das crianças de zero a seis anos, em parceria com a família e a comunidade;

- comprometer-se com o bem-estar e o desenvolvimento integral das crianças;

- $\quad$ promover ações que assegurem um ambiente saudável e ecológico na instituição de educação infantil;

- $\quad$ refletir sobre sua própria prática de modo a buscar a coerência entre o fazer pedagógico e as concepções teóricas;

- desenvolver metodologias e estratégias de intervenção pedagógica adequadas às crianças, na perspectiva da indissociabilidade entre educar e cuidar;

- $\quad$ apropriar-se do conhecimento de teorias e pesquisas desenvolvidas na área da educação e do desenvolvimento de crianças de até seis anos;

- dominar os princípios científicos e tecnológicos que sustentam a moderna produção de conhecimento da vida contemporânea (BRASIL, 2005).

Mas será que os profissionais de educação infantil adquiriram, por meio do ProInfantil, as qualificações propostas? O que dizem as pesquisas acadêmicas sobre esse programa? Quais os avanços para a educação infantil?

Quando falamos de dilemas e desafios na educação infantil no século XXI, não podemos ignorar que ainda prevalece nas políticas públicas para essa etapa da educação básica uma lógica de investimento "barato". É possível observar a forte tendência de propostas políticas que investem na ampliação da rede pública, sem levar em conta fatores fundamentais para um atendimento de qualidade, como o atendimento integral às crianças de 0 a 3 anos de idade, o cuidado com os espaços físicos, a formação e valorização do profissional. Segundo Barreto e Oliveira:

A formação do professor é reconhecidamente um dos fatores mais importantes para a promoção de padrões de qualidade adequados na educação, qualquer que seja o grau ou modalidade. No caso da educação da criança menor, vários estudos internacionais têm apontado que a capacitação específica do profissional é uma das variáveis que maior impacto causam sobre a qualidade do atendimento (BARRETO e OLIVEIRA apud LANTER, 1999, p. 138). 
Acreditamos que o estudo que estamos propondo contribuirá para discussões, pesquisas e proposição de ações e políticas para a formação de professor de educação infantil no Brasil.

A pesquisa caracteriza-se como estudo documental. Em geral, os documentos são fonte poderosa de informação, dos quais podem ser retiradas evidências que fundamentem o trabalho do pesquisador, dando maior estabilidade aos resultados (LÜDKE \& ANDRÉ, 1986). Devemos considerar também que os documentos são produções históricas da humanidade e que sua análise deve levar em conta o contexto histórico, social, político e econômico em que foram produzidos. Como a educação é uma atividade humana social e histórica, que se organiza de forma conflituosa e contraditória, articulada com os múltiplos interesses econômicos, políticos, culturais e sociais e é estruturada da maneira como se organiza o processo de produção da existência humana no trabalho, a abordagem sóciohistórica trará contribuições importantes para a pesquisa.

Buscamos identificar nos trabalhos analisados as colaborações do Proinfantil para a formação dos professores, que fatores são considerados avanços e quais, retrocessos.

Segundo Alves-Mazzoti e Gewandsnajder:

[...] À medida que os dados vão sendo coletados, o pesquisador vai procurando tantativamente identificar temas e relações, construindo interpretações e gerando novas questões e/ou aperfeiçoando as anteriores, o que, por sua vez, o leva a buscar novos dados, complementares ou mais específicos, que testem suas interpretações, num processo de 'sintonia fina' que vai até a análise final (1998, p. 170).

Esse é o grande desafio na pesquisa: classificar o que é essencial no processo de garimpagem. Sanfelice (2004, p. 98) compreende que o recorte não tem por objetivo isolar o objeto de estudo, mas que é "[...] apenas oportuno no sentido de privilegiar a análise de um objeto específico e não no sentido de isolamento do mesmo objeto [...]".

O pesquisador precisa estabelecer um diálogo com as fontes na tentativa de compreender o objeto de estudo, problematizando a realidade em que foram produzidas, ou seja, olhando as fontes como produção e construção histórica do homem, que refletem, ao mesmo tempo, as relações estabelecidas entre esse homem e o mundo material em que ele se encontra.

É importante destacar que foi frequente a revisão da literatura sobre a formação de professor para aprofundarmos o embasamento teórico do estudo proposto. Segundo Ludke \& André (1986, p. 47), “[...] a volta à literatura pertinente durante a coleta pode ajudar muito a análise. Algumas perguntas podem, por exemplo, ser levantadas [...]". Alem disso, "relacionar as descobertas feitas durante o estudo com o que já existe na literatura é fundamental para que se possam tomar decisões mais seguras sobre as direções em que vale a pena concentrar o esforço e as atenções".

\section{Análise das produções das Reuniões da Associação Nacional dos Pós-Graduandos em Educação (Anped) e do Seminário de Grupos de Pesquisa sobre Crianças e Infâncias (Grupeci) (2008 a 2015) sobre o Proinfantil}

A coleta de dados se deu no período de abril a julho de 2015. Nesse período, foram realizadas pesquisas nas universidades públicas federais e no Banco de Dados da Capes no intuito de localizarmos teses e dissertações que versam sobre o Proinfantil. Durante o desenvolvimento do trabalho, sentimos a necessidade de pesquisar também as produções 
apresentadas em alguns eventos que são referências tanto na área da educação e um específico no campo da Educação Infantil. Assim, elegemos as Reuniões da Associação Nacional dos Pós-Graduandos em Educação (Anped) e o Seminário de Grupos de Pesquisa sobre Crianças e Infâncias (Grupeci).

Como o Proinfantil foi implementado pelo governo federal no ano de 2005, consideramos o recorte temporal para as pesquisas o período de 2008 a 2015.

No site da Anped, fizemos um levantamento dos trabalhos apresentados nos seguintes grupos de trabalho: Didática (GT 4), Estado e Política Educacional (GT 5), Educação da Criança de 0 a 6 anos (GT 7), Formação de Professor (GT 8). Localizamos somente 1 trabalho apresentado no GT 8 na $37^{\mathrm{a}}$ Reunião da Anped realizada no ano de 2015.

\begin{tabular}{|l|l|l|c|}
\hline \multicolumn{1}{|c|}{ TÍTULO } & \multicolumn{1}{|c|}{ AUTORIA } & INSTITUIÇÃO & ANO \\
\hline $\begin{array}{l}\text { Do outro que me constitui: } \\
\text { o Proinfantil e a construção } \\
\text { da identidade docente }\end{array}$ & Flávia Miller Naethe Motta & UFRRJ & 2015 \\
\hline
\end{tabular}

Foram analisados os anais do Grupeci no período de 2008 a 2014. Esse evento é realizado a cada dois anos. Foram localizados 3 trabalhos no ano de 2012 que estudam o Proinfantil, sendo que "Formação e prática docente: o Proinfantil no município de Nova Iguaçu" apresenta muitas das informações do trabalho exposto na Anped. Já "Análise dos programas de atendimento à primeira infância e a descentralização da gestão da educação" descreve o Proinfantil inserido em uma análise mais geral de outros programas para a infância.

\begin{tabular}{|c|c|c|c|}
\hline $\begin{array}{c}\text { TÍTULO } \\
\end{array}$ & AUTORIA & INSTITUIÇÃO & ANO \\
\hline $\begin{array}{l}\text { Uma avaliação do } \\
\text { Proinfantil em Pernambuco }\end{array}$ & $\begin{array}{l}\text { Juceli Bengert Lima } \\
\text { Aldenize Ferreira de } \\
\text { Lima }\end{array}$ & $\begin{array}{l}\text { CGEE - DIPES - } \\
\text { FUNDAJ } \\
\text { UFPE }\end{array}$ & 2012 \\
\hline $\begin{array}{l}\text { Análise dos programas de } \\
\text { atendimento à primeira } \\
\text { infância } \\
\text { descentralização da gestão } \\
\text { da educação }\end{array}$ & $\begin{array}{l}\text { Patrícia Maria Uchôa } \\
\text { Simões } \\
\text { Sindy de Souza Leão } \\
\text { Pereira }\end{array}$ & $\begin{array}{l}\text { Fundação Joaquim } \\
\text { Nabuco } \\
\text { Universidade Federal } \\
\text { de Pernambuco }\end{array}$ & 2012 \\
\hline $\begin{array}{l}\text { Formação e prática docente: } \\
\text { o Proinfantil no município } \\
\text { de Nova Iguaçu }\end{array}$ & $\begin{array}{ll}\text { Isabele } & \text { Lacerda } \\
\text { Queiroz } & \end{array}$ & UFRRJ & 2012 \\
\hline $\begin{array}{l}\text { Trabalho docente na } \\
\text { educação infantil: entre o } \\
\text { educar e o cuidar }\end{array}$ & $\begin{array}{l}\text { Ana Maria Cunha } \\
\text { Aguiar } \\
\text { Maria do Rosário de } \\
\text { Fátima de Carvalho }\end{array}$ & CE/UFRN & 2012 \\
\hline
\end{tabular}

Nos trabalhos analisados, foi possível identificar a defesa dos pesquisadores sobre a importância da formação do professor de educação infantil no sentido de superar um dos problemas que marcam a história dessa etapa da educação básica, ou seja, que para ser professor de crianças de 0 a 5 anos é preciso somente ser mulher e amar as crianças. A formação insere as pessoas que atuam na educação infantil no campo da profissão docente, o qual lhes garante direitos trabalhistas, bem como a valorização enquanto profissionais da educação. Além disso, segundo Mantovani e Perani (1999 apud BATISTA e ROCHA, 2015, 
p. 1), “[...] esta é uma profissão a ser inventada e a consolidação de suas funções e de sua própria denominação vem exigindo um maior conhecimento de suas origens e do percurso histórico desta constituição profissional".

Nesse sentido, acreditamos que estudar o Proinfantil nos ajuda a compreender as definições e configurações contemporâneas sobre o profissional da educação infantil nas políticas públicas e, consequentemente, a concepção de infância e criança dessas políticas. Segundo Simões e Pereira:

\begin{abstract}
Alguns programas governamentais, no âmbito do Ministério da Educação, vêm sendo desenvolvidos com o objetivo de melhorar o atendimento a essa faixa etária. A discussão sobre as formas de atendimento a crianças de 0 a 6 anos reflete as concepções de infância, cidadania e desenvolvimento de uma sociedade. As mudanças ocorridas na história determinam o que se entende por criança, de como ela pode se desenvolver, define sua participação social e como ela deve ser tratada (2012, p. 43).
\end{abstract}

Motta e Queiroz (2015), ao analisar o Proinfantil no município de Nova Iguaçu (RJ), apontam como contribuições do programa:

Em Nova Iguaçu, o PROINFANTIL formou 19 professores cursistas, oriundos de Escolas Municipais de Educação Infantil (EMEI) e Creches Comunitárias Conveniadas, que agora possuem habilitação em magistério para a educação infantil. Cabe ressaltar que esses profissionais não eram professores regentes, mas auxiliares de turma ou Agentes de Desenvolvimento Infantil (2015, p. 4).

Durante a realização do PROINFANTIL era possibilitado ao cursista refletir sobre seu lugar enquanto profissional e tomar consciência do processo identitário de sua profissão. Porém, esse movimento trouxe à tona um antigo dilema: o conflito entre professor e auxiliar, uma vez que as cursistas não são as regentes de turma. A maneira como cada uma das pesquisadas disseram se sentir professoras girava em torno do conflito sobre as possibilidades do fazer (2015, p. 5).

Os dados acima destacam um problema ainda não superado no cotidiano da educação infantil, ou seja, a dicotomia entre educar e cuidar. Mesmo que nos documentos oficiais e as diversas pesquisas e estudos na área definam que são práticas indissociáveis, sabemos que no cotidiano o que prevalece é a cisão. Isso se evidencia em vários momentos: a classificação nos concursos (auxiliar, professora de creche), a divisão de tarefas nas instituições, a abordagem feita nos cursos de Pedagogia, o imaginário ainda forte de ser a educação infantil uma atividade que exige das mulheres apenas o amor materno, a precariedade das condições de trabalho, entre outros.

Eu não sou a professora. A única coisa que eu posso fazer são as atividades de cuidado - dar banho, levar as crianças ao banheiro, botar pra dormir... A parte de preparar as atividades, de participar das reuniões é só com elas (professoras). E elas acham que não podem fazer a nossa função, porque são professoras. Então, se elas não querem fazer o nosso trabalho (de ADI) eu também não faço o delas (Caderno de campo, EMEI Visconde, $18 / 10 / 11)$. 
Entretanto, ao responder à pergunta sobre sua identidade profissional, na entrevista, Silvia foi enfática ao responder: "Eu sou professora. Tenho certeza disso. E não desisto. (...) Não vou desistir, eu sou professora, sei que eu posso" (MOTTA e QUEIROZ, 2015, p. 6).

Observa-se que, apesar dos problemas de divisão de tarefas e, consequentemente, plano de carreira, profissão etc., algumas cursistas do Proinfantil conseguiram chegar ao final do curso tendo clareza da sua formação como professora, o que as levam a vislumbrar outras possibilidades de trabalho e também crescimento profissional dentro das instituições de educação infantil. Como afirmam Motta e Queiroz:

o programa abre outras perspectivas aos profissionais que participaram da formação, ao ampliar a visão de criança como ser integral, sujeito social, que necessita de atendimento que atendam suas especificidades, e ao possibilitar, diante da formação, condições para a participação de concursos para professores do segmento, mesmo que seja em outros municípios (2015, p. 13).

Na pesquisa realizada sobre as representações sociais que as professoras cursistas do Proinfantil (Rio Grande do Norte) têm sobre trabalho docente na educação infantil, Aguiar e Carvalho identificaram que:

[...] as professoras do Proinfantil do RN, na sua maioria, possuem muitos anos de docência na educação infantil. Sem uma formação específica para ser professora de criança, elas provavelmente atuaram como docentes apoiadas na ideia e valores de uma educação guardiã e assistencialista, bastante difundida na sociedade brasileira (2012, p. 46).

[...] as professoras do Proinfantil do RN focam o trabalho docente, a docência, como categoria trabalho, numa dimensão menos valorizada que o professor. E a dimensão professor, menos valorizada que a educação infantil. Deste modo, o segundo valor seria o professor que está em busca de se qualificar, para atingir um suposto nível profissional. Percebemos claramente [...] que a palavra profissão vem junto de trabalho docente, de estudo, de escola, de ensino e de transmitir; já a palavra professor aparece na região central do mapa, a de valor intermediário, sugerindo que as próprias professoras do Proinfantil-RN não se representem como profissionais, mas encontrem-se num vir a ser através do curso que frequentam. Podemos inferir através da leitura desse mapa que ser professora da educação infantil é o grande ideal dessas professoras; no entanto, a realidade de trabalho que elas vivem já exige que desempenhem a função antes mesmo de se representarem como tal (2012, p. 50).

Considerando o aspecto sociocultural das professoras do Proinfantil-RN, constatamos que o sonho, a meta é se tornarem de fato professoras. Mas o mapa nos sugere que o valor dado à profissão do ser professor, que planeja, estuda, ler e transmite, não aparece associado a ser professor da educação infantil. Essas são as primeiras interpretações dos dados, mas nos parece que para essas professoras, o trabalho docente não acontece na etapa da educação infantil. $\mathrm{O}$ que significa a própria realidade vivenciada pelas 
mesmas, porque, por muitos anos, atenderam as crianças sem nenhuma formação específica (2012, p. 50).

Contribui para isso os discursos que foram ganhando força ao longo da nossa história, especificamente da história da criança e da mulher, a assertiva de que o magistério de educação infantil é uma área eminentemente feminina e que o "amor materno" é suficiente para garantir o bom desenvolvimento das atividades e a qualidade nas instituições de educação infantil. Nesse sentido, devemos considerar também que a discriminação em relação ao trabalho feminino é um dos fatores que contribuem para o empobrecimento das políticas de educação infantil.

Investir numa política de formação e qualificação dos profissionais que atuam em educação infantil é um dos pontos fundamentais na discussão da qualidade na educação, principalmente nas escolas públicas, que, historicamente, sempre foram negligenciadas pelas políticas públicas. Uma formação que contemple conhecimentos sobre os diversos aspectos do desenvolvimento infantil e que auxilie o profissional a refletir sobre sua prática e a buscar desenvolver no cotidiano das instituições um processo educativo que tenha como princípio a práxis.

Na pesquisa realizada sobre o Proinfantil em Pernambuco, Lima e Lima (2012) identificaram, por meio de questionário aplicado a "39 profissionais que cumpriam o momento presencial do III módulo do programa", os seguintes aspectos positivos do programa:

Em relação à aquisição de novos conhecimentos, seis professores afirmam que os momentos a distância são fundamentais para novas aprendizagens e quatro deles justificam isso, pois os momentos a distância estimulam a leitura e a realização de pesquisas

[...] Eles afirmam que as tutoras e os encontros quinzenais são imprescindíveis para aprendizagem deles, mesmo diante das dificuldades que surgem, pois permitem esclarecer as dúvidas e discutirem as temáticas, trocando experiências entre eles (LIMA e LIMA, 2012, p. 22).

No que se refere ao material didático do curso, foi possível verificar pontos positivos e negativos:

[...] duas professoras afirmaram que o material "deixava a desejar", cinco disseram que os materiais eram bons, mas fizeram algumas críticas em relação à abordagem complexa dos assuntos referentes à matemática e à linguagem; críticas pelos textos serem repetitivos ou por serem complicados. No entanto, a maioria delas afirmou que o material é muito bom pela riqueza dos conteúdos que propiciam a aprendizagem influenciando a vida profissional e particular; pelos textos terem uma linguagem que facilita a compreensão e por ser um material que pode ser utilizado em outros momentos (LIMA e LIMA, 2012, p. 24).

É importante destacar os avanços no que se refere à formação das professoras participantes da pesquisa:

Quando as educadoras foram questionadas sobre a contribuição do programa para formação profissional todas afirmaram que houve 
contribuições, sejam elas mudanças conceituais, inovação da prática, mudança institucional, compreensão do desenvolvimento das crianças, segurança (LIMA e LIMA, 2012, p. 25).

Em relação aos pontos considerados negativos, destacam que "alguns professores indicaram como negativos a necessidade de mais tempo nas aulas presenciais e o sentimento de cansaço" (LIMA e LIMA, 2012, p. 23) e que "[...] as principais dificuldades apresentadas para o programa foram o transporte, o espaço da sala de aula e o deslocamento para a agência formadora" (LIMA e LIMA, 2012, p. 27).

Consideramos um dos retrocessos do programa atribuir ao professor a responsabilidade das mudanças que deverão ocorrer na escola após a realização do curso. Esse é um dos princípios do neoliberalismo, ou seja, atribui ao sujeito a responsabilidade pelos fracassos e sucessos. Não se levam em conta fatores da ordem das diferenças sociais produzidas pelo sistema capitalista. Freitas, ao analisar as atuais políticas públicas para a educação no Brasil, destaca que:

Os atuais reformadores empresariais apenas retomam a filosofia pragmatista do começo do século passado em outros níveis de exigência tecnológica e de controle social e lhe dão aparência de "inovação" - no fundo, trata-se novamente de adaptar a escola às exigências oriundas do mundo do trabalho e, em especial, ao aumento da produtividade de forma a recompor taxas de acumulação de riqueza.

Nesta segunda onda neoliberal na educação, os reformadores chegam agora com mais força pela experiência que acumularam em 20 anos de atuação sistemática, não só no Brasil, mas especialmente dentro dos Estados Unidos (EMERY, 2002; RAVITCH, 2011a) e pelo fato de que há novos mecanismos de pressão atuando na direção da internacionalização da política educacional, dentre os quais se destacam a Organização para a Cooperação e Desenvolvimento Econômico (OCDE) e as ramificações nacionais expressas por organizações locais dirigidas e financiadas por empresários, como o Movimento Todos pela Educação no Brasil.

Estes atores, embora antigos, atuam agora com maior força dentro dos órgãos nacionais de elaboração de políticas educacionais, Ministérios, Congresso Nacional e articulam expressivo apoio da mídia liberal/conservadora, que veicula cotidianamente suas propostas, sem contar o apoio de inúmeras empresas educacionais de consultoria, ONGs e institutos privados (FREITAS, 2014, p. 1105-1106).

Essa perspectiva contribui também para a dificuldade que ainda hoje se apresenta na educação infantil, que é a definição do papel do professor nessa etapa da educação básica.

[...] essa formação, ao mesmo tempo que abriu outras possibilidades de vida aos cursistas, também tem causado sofrimento para aqueles que continuam atuando no município e buscando uma identidade que lhes dê segurança de prosseguir na profissão (MOTTA e QUEIROZ, 2015, p. 10).

Nesse sentido, destacamos que, apesar dos avanços apresentados pelo Proinfantil, principalmente por ter conseguido formar professores em diferentes regiões do país, o programa evidenciou problemas que precisamos analisar, pesquisar, debater, em busca de políticas públicas de valorização do profissional da educação infantil. 


\section{Considerações}

Pelo exposto, foi possível verificar que o Proinfantil trouxe contribuições importantes para a formação dos profissionais que não tinham o magistério, apesar do seu caráter emergencial e dos diversos problemas enfrentados para a sua concretização. Entre os avanços, consideramos a abordagem teórica de temas relacionados à educação infantil e os registros feitos pelas professoras por meio do memorial. Esse instrumento configura-se como importante registro de memórias de uma política pública, o qual traz contribuições significativas para as pesquisas na área, bem como para compreendermos o Proinfantil a partir de diferentes olhares.

Uma das dificuldades, acreditamos ser atribuir ao professor a responsabilidade da mudança na educação após a formação obtida no Programa, uma vez que não foram apresentados mecanismos de mudanças estruturais por meio de políticas públicas nos municípios que o Programa foi implementado.

Devemos levar em conta que a mudança necessária hoje no campo da educação infantil só será concretizada com o investimento nos diversos setores: ampliação de vagas, construções de unidades com qualidade e que respeitem as diversidades regionais, plano de carreira para os profissionais, melhorias salariais, relação professor aluno, investimento para que todos os profissionais tenham formação em nível superior. Além disso, o Proinfantil gera problemas sobre o perfil e identidade dos professores de educação infantil por não haver uma política de redimensionamento do cargo dos auxiliares que já atuavam como professores e que a partir do programa passam a atender à formação mínima para exercerem a função.

Compreendemos que outros estudos são necessários para obtermos maiores informações sobre os impactos do programa nos diferentes municípios em que foi implementado, principalmente sobre o número de professores formados e as funções que passaram a ocupar após o Proinfantil, ou seja, que mudanças foram efetivadas a médio e longo prazo.

\section{Referências}

AGUIAR, Ana Maria Cunha e CARVALHO, Maria do Rosário de Fátima de. Trabalho docente na educação infantil: entre o educar e o cuidar. 2012.

ALVES-MAZZOTTI, Alda Judith e GEWANDSZNAJDER, Fernando. O método nas ciências naturais e sociais: pesquisa quantitativa e qualitativa. 2. ed. São Paulo: Pioneira, 1999

BATISTA, Rosa e ROCHA, Eloísa Acires Candal. A constituição histórica da docência na educação infantil: um estudo a partir do contexto catarinense do início do século XX. In: $37^{a}$ Reunião Nacional da ANPEd - 4 a 8 de outubro de 2015, UFSC - Florianópolis.

Disponível em: http://37reuniao.anped.org.br/trabalhos/ Acesso em: 1.12.2015.

BRASIL. Lei de Diretrizes e Bases da Educação Nacional. Lei n. 9.394, de 20 de dezembro de 1996. Estabelece as diretrizes e bases da educação nacional. Diário Oficial [da República Federativa do Brasil], Brasília, DF, 23 dez. 1996.

BRASIL. PROINFANTIL: Programa de Formação Inicial para Professores em Exercício na Educação Infantil: guia geral, 2005. Brasília: Ministério da Educação, Secretaria de Educação Básica, 2005. 51 p. (Coleção Proinfantil). 
BRASIL. Lei n. 10.172, 9 de janeiro de 2001. Aprova o Plano Nacional de Educação (PNE). Diário Oficial da República Federativa do Brasil, Poder Executivo, Brasília, DF, 2001. http://www.inep.gov.br/download/cibec/2001/titulos_avulsos/miolo_PNE.pdf.

FREITAS, Luiz Carlos de. Os reformadores empresariais da educação e a disputa pelo controle. In: Educ. Soc., Campinas, v. 35, nº 129, p. 1085-1114, out.-dez., 2014

GOURLART, Maria Inês Mafra [et al.]. Quem são os professores da educação infantil?: um estudo a partir do programa ProInfantil. Olhar de Professor. Pronta Grossa, PR: UEPG, v. 16, n. 1, p. 31-47, 2013.

LANTER, Ana Paula. A política de formação do profissional de Educação Infantil: os anos 90 e as diretrizes do MEC diante da questão. In: KRAMER, Sônia. Infância e Educação Infantil. Campinas, SP: Papirus, 1999. Cap. 11, p. 269-280. (Coleção prática pedagógica).

LIMA, Juceli Bengert e LIMA, Aldenize Ferreira de. Uma avaliação do Proinfantil em Pernambuco. 2012.

LUDKE, Menga e ANDRÉ, Marli E. D. A. Pesquisa em educação: abordagens qualitativas. São Paulo: EPU, 1986. (Temas básicos de educação e ensino).

MOTTA, Flávia Miller Naethe e QUEIROZ, Isabele Lacerda. Do outro que me constitui: o Proinfantil e a construção da identidade docente. In: $37^{a}$ Reunião Nacional da ANPEd - 04 a 8 de outubro de 2015, UFSC - Florianópolis. Disponível em: http://37reuniao.anped.org.br/wp-content/uploads/2015/02/Trabalho-GT08-3925.pdf Acesso em: 28.12.2015.

SANFELICE, José Luis. Fontes e história das políticas educacionais. In: LOMBARDI, José Claudinei e NASCIMENTO, Maria Isabel Moura (Orgs.). Fontes, história e historiografia da educação. Campinas, SP: Autores Associados, 2004. (Coleção Memória da Educação).

SIMÕES, Patrícia Maria Uchôa e PEREIRA, Sindy de Souza Leão. Análise dos programas de atendimento à primeira infância e a descentralização da gestão da educação. In: III Seminário de Grupos de Pesquisa sobre Crianças e Infâncias. GRUPECI. Universidade Federal de Sergipe/Departamento de Educação, Sergipe, 2012.

\footnotetext{
${ }^{1}$ O presente artigo integra a pesquisa realizada, em 2015, no pós-doutoramento na Faculdade de Educação da Universidade de São Paulo (FEUSP). Apoio da Universidade Estadual do Sudoeste da Bahia (UESB).

${ }^{2}$ Universidade de São Paulo - USP.

Universidade Estadual do Sudoeste da Bahia - UESB.
}

Recebido: Março/2016.

Aprovado: Março/2017. 